\title{
Egg source, temperature and culture seawater affect elemental signatures in Kelletia kelletii larval statoliths
}

\author{
Diana C. Lloyd ${ }^{1}$, Danielle C. Zacherl ${ }^{1, *}$, Sean Walker ${ }^{1}$, Georges Paradis ${ }^{2}$, \\ Michael Sheehy ${ }^{2}$, Robert R. Warner ${ }^{3}$ \\ ${ }^{1}$ Department of Biological Science, PO Box 6850, California State University Fullerton, Fullerton, California 92834-6850, USA \\ ${ }^{2}$ Marine Science Institute and ${ }^{3}$ Department of Ecology, Evolution and Marine Biology, University of California Santa \\ Barbara, Santa Barbara, California 93106, USA
}

\begin{abstract}
Elemental signatures have been used as a tool to track individual organisms to their natal site in an attempt to understand stock structure and larval dispersal. However, factors that affect elemental signatures are not well understood. We conducted a factorial experiment using whelk Kelletia kelletii larvae from Salta Verde Point on Catalina Island, Los Angeles Harbor, and White Point, Palos Verdes peninsula, California, USA, to test the effects of egg source, temperature $(10,14$ and $18^{\circ} \mathrm{C}$ ) and culture seawater on the elemental composition of larval statoliths. Intra-capsular contents of newly laid capsules were also analyzed to explore whether maternal contributions might affect larval statolith chemistry. Using inductively coupled plasma mass spectrometry we quantified ratios of 7 elements to calcium in both intra-capsular contents and cultured statoliths and provided the first evidence of significant egg-source effects, independent of subsequently experienced environmental conditions, on statolith elemental signatures for $\mathrm{Mg}: \mathrm{Ca}, \mathrm{Ba}: \mathrm{Ca}$ and $\mathrm{Pb}: \mathrm{Ca}$. Intra-capsular and statolith element ratios showed no clear relationship that might have indicated possible maternal transfer of elements to larvae. Culture seawater elemental concentration was positively related to statolith $\mathrm{Ba}: \mathrm{Ca}$ and $\mathrm{Pb}: \mathrm{Ca}$, and temperature was negatively related to statolith $\mathrm{Sr}: \mathrm{Ca}, \mathrm{Ba}: \mathrm{Ca}$ and $\mathrm{Pb}: \mathrm{Ca}$, while no significant effects were found for Mn:Ca or Zn:Ca. Effect-size estimates show that elements responded differently to factors within the variation measured in this study; the major effects for $\mathrm{Ba}$ and $\mathrm{Pb}$ were temperature and egg source, respectively. The significant effect of egg source on elemental signatures has potentially important implications for tracking free-spawned larvae.
\end{abstract}

KEY WORDS: Statolith $\cdot$ LA ICP-MS · Dispersal $\cdot$ Egg source $\cdot$ Relative effects $\cdot$ Elemental signature Kelletia kelletii

\section{INTRODUCTION}

Biogenic carbonates (e.g. foraminiferal shell calcite, coral aragonite) have been used for decades as recorders of environmental variation. Elements bound within calcified structures can provide historic information on climate change (Lea et al. 2000), oceanic nutrient geochemistry (Lea et al. 1989) and El Niño Southern Oscillations (Shen \& Sanford 1990).
In recent years fishery scientists have used calcified structures of fish (e.g. otoliths) and invertebrates (e.g. statoliths, shells and carapaces) to reconstruct the environmental histories of individual organisms. Theoretically, as individuals move across gradients in temperature, salinity or ambient aquatic chemistry their movements are recorded in the elemental composition of their calcified parts. Thus, elements in fish otoliths and squid statoliths have been used successfully as 
natural signatures of stock structure (e.g. Campana et al. 2000), as records of dispersal and migration pathways (e.g. Ikeda et al. 2003) and for identifying spawning and nursery grounds (e.g. Gillanders \& Kingsford 2003).

In particular, the elemental composition of the larval calcified structures of fish (Swearer et al. 1999), crabs (DiBacco \& Levin 2000), bivalves (Becker et al. 2007) and gastropods (Zacherl 2005) has potential to elucidate much useful information about larval origin and dispersal trajectories. Many larvae begin forming their calcified structures at or near the site of production and, thus, potentially carry a permanent elemental signature of the site of origin. When larvae enter the water column and move through ocean masses with variable physical and chemical characteristics, these changes can be recorded in the elemental composition of calcified structures. In principle, not only can the site of origin be identified, but subsequent larval movement also can be tracked using statolith elemental signatures.

To identify any particular settler's site of origin the elemental signature of the portion of the calcified structure formed before the individual's release at or near the site of origin must be matched to the unique elemental composition of the site of origin. While the approach is straightforward, the sampling procedure is complicated. All potential source populations must first be identified and spatial variation of the signatures among those potential sources must be documented and mapped. Signatures that vary temporally may require the compilation of a library of elemental signatures over several years to assign a sample to a potential source population with confidence (Gillanders 2002). Finally, the elemental signature in the calcified structure may be analyzed in post-settlement individuals and matched to signatures of potential source populations. Because collection and analysis of samples is costly and time consuming, research would be greatly facilitated if it were possible to use environmental data such as seawater chemical composition and temperature to predict elemental signatures of potential source populations (Warner et al. 2005).

Predicting a site's elemental signature requires an understanding of the factors that influence element uptake, especially in larval structures. Laboratory culture studies have demonstrated that salinity (e.g. Chang et al. 2004), elemental composition of the culture water (e.g. Bath et al. 2000, Elsdon \& Gillanders 2003), temperature (e.g. Bath et al. 2000, Zacherl et al. 2003) and diet (Farrell \& Campana 1996) can affect the elemental composition of otoliths and statoliths. Single factor laboratory studies are useful for developing general rules about element uptake, but it can be difficult to trace the effects of factors in the field where calcified structures are probably influenced by multiple interacting factors. Accordingly, several laboratory culture studies of the otoliths and statoliths of larvae (e.g. Zacherl et al. 2003, Bath Martin \& Thorrold 2005) and juveniles (e.g. Milton \& Chenery 2001, Elsdon \& Gillanders 2004) have examined the interactive effects of 2 or more of the above factors. However, only one study attempted to rank the relative importance of the factors studied. Using backwards step-wise regression, Elsdon \& Gillanders (2004) eliminated the effect of salinity and determined that temperature and ambient element concentration were the most important factors that affected the barium $(\mathrm{Ba})$ and strontium $(\mathrm{Sr})$ ratios to calcium $(\mathrm{Ca})$ in black bream Acanthopagrus butcheri otoliths. If efforts to predict elemental signatures are to be successful, a much more precise understanding of the influence and relative importance of multiple factors must be obtained.

Not only is predicting elemental signatures a complex undertaking, but even interpreting patterns of variation observed in the field is challenging, despite the knowledge gained from laboratory studies. Several field studies have demonstrated spatial variation in the chemistry of larval calcified structures (e.g. DiBacco \& Levin 2000, Warner et al. 2005, Zacherl 2005) and that temporal variation is often sufficiently stable for discriminating among individuals produced at different sites (e.g. Zacherl 2005). There has also been some success in field studies with attempts to correlate salinity or temperature with $\mathrm{Ba}$ and $\mathrm{Sr}$ in calcified structures (e.g. Ikeda et al. 1999). However, correlating the elemental content of seawater with elemental signatures in calcified structures remains elusive despite overwhelming evidence from laboratory studies demonstrating the importance of this factor. The challenge is that the chemistry of calcified structures reflects an integrated signal developed over the entire period of formation when the organism had been exposed to multiple and changing environmental factors. Therefore, a single water sample collected at a particular point in time may not be reflected in the chemistry of the calcified structure. One ambitious field study (Warner et al. 2005) attempted to link seawater and otolith chemistry with the goal of using seawater chemistry as a proxy for larval otolith signatures. Unfortunately, for all but one element (manganese), neither of the 2 physical proxies examined, including seawater elements and a resin-based element accumulator that can sample several trace elements for up to several weeks (Zhang \& Davison 1995) showed even qualitative geographic patterns that coincided with those found in larval otoliths.

Failure to find clear links between seawater chemistry and the elemental composition of calcified structures leaves open the possibility that other, yet uniden- 
tified, factors may be generating variation among sites. For example, maternal transfer of elements to the progeny's calcified structures via yolk has been suspected (Brophy et al. 2004, Ruttenberg et al. 2005, Chittaro et al. 2006); element enrichment was found in the cores of juvenile otoliths in several species of fish and it was speculated that, among other factors, the enrichment was due to maternal contributions of elements to the eggs. Building on work by Rieman et al. (1994) and Limburg et al. (2001) who initially investigated transgenerational marking, Thorrold et al. (2006) provided conclusive evidence for the maternal transfer of elements via yolk. They injected both a benthic species and a broadcast spawning species of fish with ${ }^{137} \mathrm{Ba}$ and detected elevated levels of ${ }^{137} \mathrm{Ba}$ in the resulting progeny. Maternal contributions could generate site-specific elemental signatures in larval structures due to spatial variation in factors such as maternal diet, bioavailability of elements to mothers and physiological differences among populations. Therefore, as larvae develop they may incorporate elements contained in the yolk into their calcified structures. The resultant chemistry of the calcified structure then might be at least partially independent of environmental conditions experienced by the larva as the calcified structure forms. Thus, elemental signatures of calcified structures might be reflective of both environmental conditions at the site of development and maternal contributions.

In controlled laboratory experiments, we cultured larvae in 3 seawater treatments (seawater collected from 3 field locations) to determine whether egg source, independent of subsequently experienced environmental factors (e.g. temperature, ambient elemental concentration), affects the elemental signatures of larval statoliths in the whelk, Kelletia kelletii. In addition we tested whether interactions between egg source, temperature and ambient elemental concentration exist. We also tested whether elements deposited in K. kelletii eggs are correlated with elements incorporated in larval statoliths. Finally, given the variation measured for the conditions in this study, we determined the relative importance of each of the 3 factors examined.

\section{MATERIALS AND METHODS}

Study organism. Kelletia kelletii is a predatory buccinid marine gastropod, commonly found on subtidal rocky reefs from Baja California, Mexico, to Monterey Bay, California, USA (Herrlinger 1981). This species was ideal for this study because (1) larvae are deposited in egg capsules on hard substrata, making them easy to manipulate, (2) eggs may have a sufficient amount of yolk to make maternal transfer of elements a possibility, (3) hatchlings have well developed statoliths and shell before release into the plankton, but the statoliths do not develop until about 2 wk after egg capsules are laid when they are at post-trochophore stages and (4) planktonic duration is between 6 and 8 wk (M. Romero unpubl. data), allowing enough time for substantial larval exchange among populations. Females lay clutches of 20 to 80 egg capsules (Zacherl et al. 2005), each containing between 400 and 1000 eggs (Rosenthal 1970). Larvae develop in egg capsules for about $30 \mathrm{~d}$ before they hatch into the water column as veligers that continue to feed on both yolk and phytoplankton (D. C. Lloyd pers. obs.).

Experimental design. Using eggs and seawater collected from 3 sites in southern California, we set up a factorial experiment with all possible combinations of egg source, culture seawater and culture temperature $\left(10,14\right.$ and $\left.18^{\circ} \mathrm{C}\right)$ to examine the individual and interactive effects of these factors on the elemental signatures of statoliths of Kelletia kelletii larvae. Culture seawater (collected in acid leached 208.2 l plastic drums) and egg capsules (collected in Ziplock bags) were collected at (1) Salta Verde Point (CAT) on the south side of Santa Catalina Island, (2) Los Angeles Harbor (LA) and (3) White Point (PV) off the Palos Verdes peninsula (Fig. 1); Table 1 summarizes all collection dates and locations. The sites were chosen based on the assumption that chemical and physical characteristics in the seawater would vary substantially enough to influence statolith chemistry. Salta Verde Point is about $55 \mathrm{~km}$ from the mainland and does not receive direct runoff from the few developed

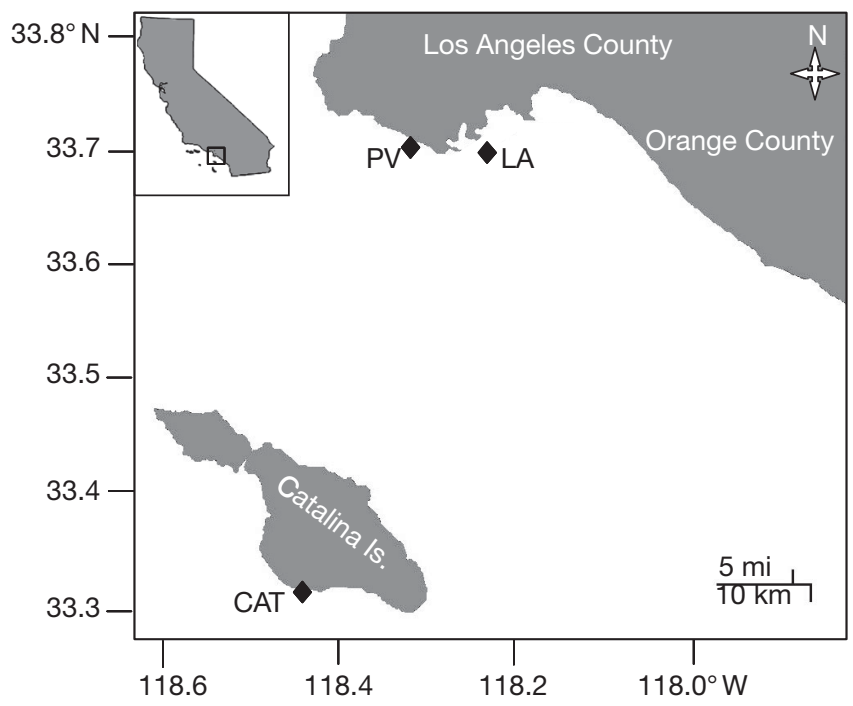

Fig. 1. Collection sites in southern California: $\mathrm{CAT}=$ Salta Verde Point, Catalina Island; LA = Los Angeles Harbor; PV = White Point, Palos Verdes peninsula 
Table 1. Kelletia kelletii. Field site coordinates, mean, highest and lowest site temperatures $\left(\mathrm{T},{ }^{\circ} \mathrm{C}\right)$, and culture seawater and egg capsule collection dates (month/day/year). Water temperatures recorded at $12.5 \pm 1.5 \mathrm{~m}$, Water $=$ seawater used for cultures collected at $3.0 \pm 0.5 \mathrm{~m}$ (see Fig. 1 and text for description of site abbreviations)

\begin{tabular}{|c|c|c|c|c|c|c|}
\hline Site & Location & Mean T & Highest $\mathrm{T}$ & Lowest $\mathrm{T}$ & Water & $\begin{array}{c}\text { Egg } \\
\text { capsules }\end{array}$ \\
\hline CAT & $\begin{array}{l}33^{\circ} 19.188^{\prime} \mathrm{N} \\
118^{\circ} 27.160^{\prime} \mathrm{W}\end{array}$ & $14.2 \pm 1.6$ & 17.91 & 11.33 & $6 / 2 / 05$ & $6 / 7 / 05$ \\
\hline LA & $\begin{array}{l}33^{\circ} 42.631^{\prime} \mathrm{N} \\
118^{\circ} 19.060^{\prime} \mathrm{W}\end{array}$ & $13.7 \pm 2.1$ & 19.84 & 10.38 & $6 / 6 / 05$ & 6/9/05 \\
\hline PV & $\begin{array}{l}33^{\circ} 42.671^{\prime} \mathrm{N}, \\
118^{\circ} 14.660^{\prime} \mathrm{W}\end{array}$ & $12.9 \pm 1.8$ & 19.86 & 10.85 & $6 / 3 / 05$ & $6 / 8 / 05$ \\
\hline
\end{tabular}

areas on the island, and, thus, we expected this site to be mostly free of metals associated with municipal runoff. Los Angeles Harbor is a large commercial port with constant boat traffic. In addition, the harbor receives industrial and urban runoff (nonpoint source pollution) from both the Dominguez and Los Angeles River watersheds that combine to include the majority of the Los Angeles basin. Thus, we presumed that the LA site would be characterized by high levels of metal contaminants (e.g. barium, lead and zinc) associated with industrial and municipal runoff. In addition to industrial and urban runoff, White Point is associated with a sewage outfall that discharges approximately $1.2 \times 10^{10} \mathrm{l} \mathrm{d}^{-1}$ (Stull 1995) and is approximately $3 \mathrm{~km}$ offshore. Sewage outfall often contains elevated levels of zinc and cadmium (Oakden et al. 1984). Significant upwelling is possible at this site because the shelf extends approximately $3 \mathrm{~km}$ offshore to the San Pedro Escarpment where it drops abruptly down to approximately $800 \mathrm{~m}$ into the San Pedro basin (Maptech Inc. [www.freeboatingcharts.com] 2005, San Pedro Channel [map], no. 18746, Edn 36). Following upwelling events, elevated levels of barium and/or manganese could be possible at this site.

Seawater was collected at a depth of $3 \pm 0.5 \mathrm{~m}$ with a PTFE tube attached to an acetal thermoplastic foot valve (Standard Flow D-25 by WATERRA), which was agitated vertically by hand to pump the seawater upward. As seawater was collected it was pre-filtered at the inlet with a $100 \mu \mathrm{m}$ mesh screen, filtered to $0.45 \mu \mathrm{m}$ mid-stream and finally filtered to $0.22 \mu \mathrm{m}$ just before the outlet. Seawater was also sampled with a $3 \%$ nitric acid rinsed horizontal Van Dorn bottle (Wildlife Supply) at $3 \pm 0.5 \mathrm{~m}$ for element analysis. Seawater for the culture experiments was stored in acid leached 208.2 l plastic containers and the cultures were maintained in acid rinsed $250 \mathrm{ml}$ plastic culture flasks (Falcon ${ }^{\mathrm{TM}}$ polystyrene with plug-seal cap).
Egg capsules were collected within a few days after they had been laid (indicated by the lack of larval pigmentation and a creamy appearance) to avoid the possibility of newly forming statoliths. Larvae of Kelletia kelletii begin forming their statoliths approximately $2 \mathrm{wk}$ (D. C. Zacherl pers. obs.) after egg capsules are laid, at which point larval pigmentation is clearly visible. After egg capsules from each site were collected they were maintained in the laboratory at $14^{\circ} \mathrm{C}$ in $0.2 \mu \mathrm{m}$ filtered seawater collected from the pier at the Scripps Institution of Oceanography in San Diego until the culturing experiment was started on June 14, 2005; egg capsules from CAT, LA and PV were maintained in these conditions for 7, 5, and $6 \mathrm{~d}$, respectively, and none of the larvae had developed any calcified structures when the experiment began. At the beginning of the culturing period encapsulated larvae from all the sites were confirmed to be at pre-trochophore to early trochophore stage by microscopic observation (10× power) and through light diffraction filters that allowed for easy detection of calcium carbonate; calcified structures were not present in any pre-culture larvae. All possible combinations of treatments with egg capsules and culture seawater from each site, and 3 temperatures (10, 14 and $18^{\circ} \mathrm{C}$ ) were represented in the experiment for a total of 27 treatment groups. These temperatures were chosen because they bracket the full range of temperatures experienced by $K$. kelletii in the field throughout its range.

Experiments were performed in temperature controlled growth chambers under $\sim 9000 \mathrm{~W} \mathrm{~m}^{-2}$ provided by a $15 \mathrm{~W}$ fluorescent tube with 12:12 h light:dark cycles. To ensure the range of temperatures in our culturing experiment bracketed those among field sites, TidBit $^{\circledR}$ temperature loggers were placed at each site (June 2005) at a depth of $12.5 \pm 1.5 \mathrm{~m}$ and temperature recorded every $3 \mathrm{~min}$ for the month of peak larval development in the field.

Egg capsules from each site were detached at the peduncle and separated into 3 containers with equal representation from all clutches. Each of the 3 containers was then randomly assigned a temperature treatment. Five egg capsules were chosen haphazardly from each of the 3 sets of egg capsules and placed in one of 5 replicate jars for each combination of treatments with culture seawater. Thus, we ensured all treatments with eggs from a site had equal representation of clutches. Fifty percent water changes were performed 3 times a week with seawater corresponding to the assigned treatment. During each water change 
seawater from a randomly selected group of 4 or 5 flasks was sampled to test for changes in the concentration of seawater elements over the course of the experiment. The $50 \mathrm{ml}$ seawater samples were immediately acidified with $50 \mu \mathrm{l}$ of $12 \mathrm{~N} \mathrm{HCl}$ and stored at $4^{\circ} \mathrm{C}$. Larvae were cultured until egg capsules appeared dark grey in color and the veliger larvae could be observed moving within the capsule, indicating that they were about to hatch; egg capsules were then frozen for subsequent analysis.

Statolith extraction. The statolith isolation and cleaning steps were performed using standard clean lab procedures. All glassware was cleaned with Citranox ${ }^{\mathrm{TM}}$ soap, rinsed 5 times with distilled $\mathrm{H}_{2} \mathrm{O}$ (resistivity $>2 \mathrm{M} \Omega \mathrm{cm}$ ), soaked overnight in $1 \mathrm{~N}$ trace metal grade $\mathrm{HCl}$ and then rinsed 5 times with ultrapure $\mathrm{H}_{2} \mathrm{O}$ (resistivity $>18.1 \mathrm{M} \Omega \mathrm{cm}$ ). Egg capsules were handled with acid rinsed Teflon forceps where practicable, but were also handled with polyethylene gloves when necessary. We analyzed 1 egg capsule from each replicate jar resulting in 5 replicate samples per treatment (egg source $\times$ culture seawater $\times$ temperature). Egg capsules were rinsed with ultrapure $\mathrm{H}_{2} \mathrm{O}$ (resistivity $>18.1 \mathrm{M} \Omega$ $\mathrm{cm}$ ) before the statoliths were extracted; this served to remove any exterior debris and thaw the capsule.

Larvae were removed from the capsule by cutting the peduncle with a sterile scalpel and squeezing the larvae out onto a clean glass slide that had been rinsed with ultrapure $\mathrm{H}_{2} \mathrm{O}$. They were then immediately transferred to an acid-washed $50 \mathrm{ml}$ beaker by squirting with ultrapure $\mathrm{H}_{2} \mathrm{O}$ to a total volume of $5 \mathrm{ml}$. Five milliliters of an equal volume mixture of Ultrapure $30 \% \mathrm{H}_{2} \mathrm{O}_{2}$ buffered with $1 \mathrm{~N} \mathrm{NaOH}$ (hereafter referred to as the 'cleaning solution') were added to the beaker and heated at $65^{\circ} \mathrm{C}$ for $12 \mathrm{~min}$. After heating the statoliths dropped out of solution to the bottom of the beaker and were concentrated in the middle of the beaker by vigorous swirling. The remaining steps were performed in a Class 100 (equiv. ISO Class 5) laminar flow hood.

The statoliths were pipetted into a new acid leached $50 \mathrm{ml}$ beaker and the cleaning solution was aspirated down to a volume of $10 \mathrm{ml}$. The beaker was then filled to $40 \mathrm{ml}$ with ultrapure $\mathrm{H}_{2} \mathrm{O}$ and aspirated down again for a total of 5 rinses, after which the statoliths were pipetted onto an acrylic plastic slide. Excess water was pipetted off the statoliths and the slide was stored in a sterile, plastic $35 \times 10 \mathrm{~mm}$ Petri dish and allowed to dry overnight in a Class 100 laminar flow hood. Just before analysis statoliths were mounted onto double sided tape $\left(\mathrm{Scotch}^{\mathrm{TM}}\right)$ and secured to the slide for laser ablation.

Statolith element analysis. We assayed for a suite of 8 elements: calcium-48 (Ca), magnesium-24 (Mg), strontium-86 (Sr), barium-138 (Ba), lead-208 (Pb), manganese-55 (Mn), zinc-66 (Zn) and cerium-140 (Ce). All elements except Ce reliably yielded detectable concentrations in statolith samples, thus, Ce was subsequently excluded from analyses. Ten haphazardly chosen statoliths from each slide were introduced via a VG-UV microprobe Nd:YAG laser, frequency-quadrupled to $266 \mathrm{~nm}$ with a nominal beam width of $20 \mu \mathrm{m}$, into a Finnigan Element 2 sector field inductively coupled plasma mass spectrometer (ICP-MS) using a micro-flow nebulizer at $20 \mu \mathrm{min}^{-1}$. Statoliths were completely consumed by the ablation (see Zacherl et al. 2003 for further discussion about statolith ablation). Sensitivity was approximately $1 \times 10^{6}$ counts $\mathrm{s}^{-1}$ for $1 \mathrm{ppb}$ indium (In). Samples from each treatment were analyzed randomly to minimize the effects of instrument drift on the results. The plasma conditions were kept constant during analysis of standards, instrument blanks and laserablated samples by constantly aspirating a $1 \% \mathrm{HNO}_{3}$ solution, which was the matrix for both the standards and the blanks (see Zacherl et al. 2003). Matrixmatched, solution-based standards of known element-to-calcium ratio and a mass bias correction applied to the instrument were used to determine the element-to-calcium ratio of the sample (Rosenthal et al. 1999). To check the accuracy and precision of our solution-based measurements we used a consistency standard containing $\mathrm{Ca}, \mathrm{Mg}, \mathrm{Sr}, \mathrm{Ba}$ and $\mathrm{Mn}$ (Spex Certified primary standard solutions): $\mathrm{Mg}: \mathrm{Ca}$ (mmol $\left.\mathrm{mol}^{-1}\right)=3.87 \%, \mathrm{Sr}: \mathrm{Ca}\left(\mathrm{mmol} \mathrm{mol}^{-1}\right)=2.64 \%, \mathrm{Ba}: \mathrm{Ca}$ $\left(\mu \mathrm{mol} \mathrm{mol}{ }^{-1}\right)=8.97 \%, \mathrm{Mn}: \mathrm{Ca}\left(\mathrm{mol} \mathrm{mol}{ }^{-1}\right)=5.52 \%$ $(\mathrm{N}=244)$. We also used National Institute of Standards and Technology (NIST)-612 glass standards as reference materials from which we could estimate the precision of the laser ablation method. The repeatability (relative $\mathrm{SD}, \% \mathrm{rSD}$ ) of the method was determined using the results of laser ablated NIST612 standard reference material except for $\mathrm{Sr}: \mathrm{Ca}$, which was determined using an unspecified otolith material: $\mathrm{Mg}: \mathrm{Ca}\left(\mathrm{mmol} \mathrm{mol}^{-1}\right)=18.8 \%, \mathrm{Sr}: \mathrm{Ca}(\mathrm{mmol}$ $\left.\mathrm{mol}^{-1}\right)=9.09 \%, \mathrm{Ba}: \mathrm{Ca}\left(\mu \mathrm{mol} \mathrm{mol}{ }^{-1}\right)=14.4 \%, \mathrm{~Pb}: \mathrm{Ca}$ $\left(\mu \mathrm{mol} \mathrm{mol}{ }^{-1}\right)=14.6 \%, \mathrm{Mn}: \mathrm{Ca}\left(\mu \mathrm{mol} \mathrm{mol}{ }^{-1}\right)=14.7 \%$, $\mathrm{Zn}: \mathrm{Ca}\left(\mu \mathrm{mol} \mathrm{mol}{ }^{-1}\right)=38.0 \%(\mathrm{~N}=48$ for all elements except $\mathrm{Zn}$ where $\mathrm{N}=47$ ).

We quantified element concentrations using our matrix-matched standard solution instead of the NIST standard because the NIST glass lacks the aragonite-dominated matrix of statoliths. Our use of solution-based standards is robust as suggested by the quantitative agreement between aragonite-dominated matrix-matched materials analyzed in solution versus laser-based modes (Thorrold et al. 1997). It is important to note, however, that the lack of certified matrixmatched solid reference materials means that our data should be compared with other studies with caution 
(Campana 1999). Following Swearer et al. (2003) we calculated detection limits for each element by calculating the standard deviation (SD) of the intensities of the elements in $1 \%$ nitric acid $\left(\mathrm{HNO}_{3}\right)$ instrument blanks and then multiplying the $\mathrm{SD}$ by 3 . That value was then added to the blank mean for each element and used as the minimum detectable signal. The intensities of blank-subtracted samples averaged $>100$ times the detection limit for ${ }^{48} \mathrm{Ca}_{1}>30$ times for $\mathrm{Mg}_{1}>20$ times for $\mathrm{Sr},>30$ times for $\mathrm{Zn},>8$ times for $\mathrm{Ba}$, $>1.5$ times for $\mathrm{Pb}$ and $>3$ times for $\mathrm{Mn}$. To control for differences in statolith sample mass we analyzed for the ratio of each element to ${ }^{48} \mathrm{Ca}$, which is consistent with the convention for trace element analysis in otoliths and statoliths (e.g. Campana 1999).

Intra-capsular contents analysis. Capsules from 10 clutches of eggs frozen before development of any calcified structures (i.e. pre-trochophore) were randomly chosen from each of the 3 sites (CAT, LA and PV). One egg capsule was haphazardly chosen from each clutch ( $\mathrm{n}=10$ capsules per site) for analysis. The intra-capsular contents were removed from each individual egg capsule (as described previously for the larvae), dried in an oven for $16 \mathrm{~h}$ at $65^{\circ} \mathrm{C}$ and weighed. For analysis via ICP-MS the intra-capsular contents of each egg capsule were then digested in ultra-pure $\mathrm{HNO}_{3}$ and diluted. We did not keep track of which clutch each egg capsule was from; thus, we were unable to analyze the results for each capsule individually, and samples from each site had to be pooled for statistical analysis. To ensure quality data a method of standard additions (Spex Certified primary standard solutions) with internal standards including scandium $(\mathrm{Sc})$, yttrium (Y) and indium (In) was used. Scandium was the internal standard for $\mathrm{Mg}$ and $\mathrm{Ca}$, $\mathrm{Y}$ was the internal standard for $\mathrm{Sr}$, and In was the internal standard for Ba and Pb. Since the CAT samples were much larger than the LA or PV samples, it was necessary to dilute CAT digests to $100 \times$, while LA and PV digests were diluted to $10 \times$.

Seawater analysis. Both the laboratory and field seawater samples were analyzed via ICP-MS using serial dilution of the samples. For barium we applied a method of isotope dilution using a standard enriched in

${ }^{135} \mathrm{Ba}$ (Oak Ridge National Laboratory $\mathrm{Ba}\left(\mathrm{CO}_{3}\right)_{2}$ salt), and determined the ${ }^{135} \mathrm{Ba} /{ }^{138} \mathrm{Ba}$ ratio. For the other elements analyzed we used a method of standard additions (Spex Certified primary standard solutions) with internal standards; Sc was the internal standard for $\mathrm{Ca}$, $\mathrm{Mn}$ and $\mathrm{Zn}, \mathrm{Y}$ was the standard for $\mathrm{Sr}$, and In was the standard for $\mathrm{Pb}$. We have not yet developed a method to analyze for $\mathrm{Mg}$ in seawater; thus, no $\mathrm{Mg}$ data were collected for the culture seawater samples.

Statistics. Effects and possible interactions of egg source, culture seawater and temperature on element- to-calcium ratios in statoliths were analyzed via a nested 3-way ANOVA for each element; replicate statoliths on a slide (from a single egg capsule) were nested and randomized within each treatment. We then compared differences among sites in statolith elemental ratios to calcium using a Tukey's multiplecomparisons procedure. We also tested for differences among sites in element-to-calcium ratios in the intracapsular contents via a 1-way ANOVA followed by Tukey's multiple comparisons. Finally, we tested for differences in element-to-calcium ratios in the culture seawater among sample dates and among sites using a 2-way ANOVA followed by a Tukey's multiple comparisons procedure. Data that did not meet ANOVA assumptions were $\log$ - or $\log (x+1)$-transformed, and included all elements in the statolith data, $\mathrm{Pb}$ and $\mathrm{Zn}$ in the seawater data and the $\mathrm{Ba}$ in the intra-capsular data. Regression analyses tested for relationships between culture seawater and statolith elemental ratios, temperature and statolith elemental ratios, and intra-capsular and statolith elemental ratios. Statistical analyses were conducted using SAS statistical software (version 9.1).

To determine which of the factors was most influential on statolith chemistry within the constraints of the variation measured in our experiment, we estimated the relative effect size of each factor for each element analyzed using partial $\eta^{2}$, which is estimated by:

$$
\eta^{2}=\frac{\text { SS effect }}{(\text { SS effect }+ \text { SS error })}
$$

This is a measure of the percentage of variance explained by a particular factor (Grissom \& Kim 2005). To avoid complications from the mixed model, we simplified the analysis by calculating the mean statolith elemental concentration per culture flask and performed a 3-factor ANOVA; in all cases the results corresponded to the nested 3-way models. This simplification also allowed us to calculate 95\% confidence intervals (CIs) for the measures of effect size. We calculated exact CIs based on the noncentral $F$ distribution (Fidler \& Thompson 2001). However, since this method assumes balanced data and our data were unbalanced, we also calculated $95 \%$ CIs using a bootstrap resampling procedure in R (version 2.4.0; Roff 2006). Bootstrap samples were generated in proportion to the number of jars within a particular combination of treatments (e.g. eggs from CAT, water from LA, cultured at $18^{\circ} \mathrm{C}$ ) and 1000 bootstrap samples were used to generate percentile-based CIs for $\eta^{2}$. Since the data were slightly unbalanced and the bootstrap estimates were similar to the exact intervals, we only present the bootstrap intervals. 


\section{RESULTS}

\section{Culturing conditions}

Element-to-calcium ratios in the culture seawater were significantly $(\mathrm{p}<0.05)$ different among sites for Ba:Ca $\left(F_{2,64}=11.86, \mathrm{p}<0.0001\right), \mathrm{Pb}: \mathrm{Ca}\left(F_{2,64}=7.61, \mathrm{p}=\right.$ $0.0011)$ and Mn:Ca $\left(F_{2,64}=25.06, \mathrm{p}<0.0001\right)$, but not for Sr:Ca $(p=0.8380)$ or $\mathrm{Zn}: \mathrm{Ca}(\mathrm{p}=0.1896)$ (Fig. 2). Because we archived one water sample from each site for use in the cultures, we tested for differences in elemental ratios over storage time. Culture seawater samples showed no significant change over time in the elemental ratios of $\mathrm{Ba}: \mathrm{Ca}(\mathrm{p}=0.3923), \mathrm{Pb}: \mathrm{Ca}(\mathrm{p}=0.1925)$ or Sr:Ca ( $\mathrm{p}=0.0781)$, but did show a significant change over time for Mn:Ca $\left(F_{18,64}=4.16, \mathrm{p}<0.0001\right)$ and $\mathrm{Zn}: \mathrm{Ca}\left(F_{18,64}=2.01, \mathrm{p}=0.0219\right)$. Temperatures in the growth chambers were stable at the set temperatures $\left(10.45 \pm 1.05,14.44 \pm 0.79\right.$ and $\left.18.87 \pm 0.86^{\circ} \mathrm{C}\right)$ and bracketed the full range of temperatures measured in the field (Table 1).

\section{Factorial experiment}

Egg-source effects. Egg source significantly $(p<0.05)$ affected the elemental signatures of $\mathrm{Mg}: \mathrm{Ca}, \mathrm{Ba}: \mathrm{Ca}$ and $\mathrm{Pb}$ :Ca in statoliths of laboratory cultured Kelletia kelletii larvae (Fig. 3, Table 2). Average values of $\mathrm{Mg}$ : $\mathrm{Ca}$ and $\mathrm{Ba}: \mathrm{Ca}$ in statoliths over all treatments plotted against egg source indicate that $\mathrm{Mg}: \mathrm{Ca}$ and $\mathrm{Ba}: \mathrm{Ca}$ were higher in statoliths from CAT regardless of the origin of the culture seawater or the temperature treatment (Fig. 3). Similarly $\mathrm{Pb}$ :Ca was lowest in statoliths from LA (Fig. 3), which is contrary to our original assumptions. Elemental ratios not significantly affected by egg source included $\mathrm{Sr}: \mathrm{Ca}$, $\mathrm{Zn}: \mathrm{Ca}$ and $\mathrm{Mn}: \mathrm{Ca}$, despite the fact that $\mathrm{Mn}: \mathrm{Ca}$ was significantly different in seawater among sites.
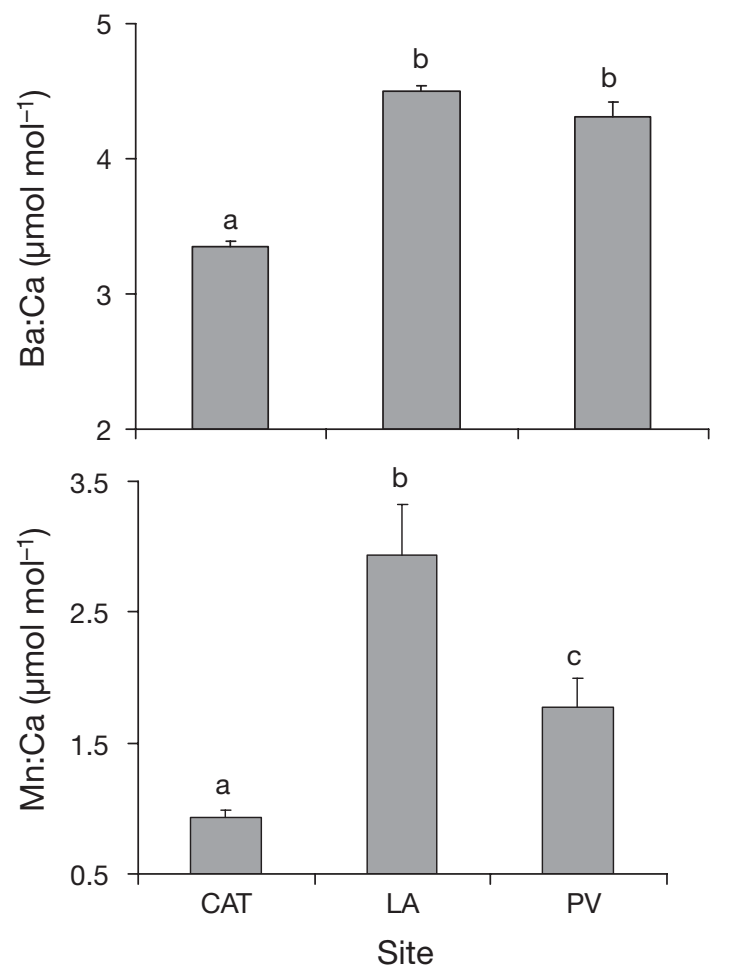

Fig. 2. Mean (+SE) element-to-calcium ratios for culturing seawater collected from 3 sites in southern California (see Fig. 1): CAT, $\mathrm{n}=29$; LA, $\mathrm{n}=27 ; \mathrm{PV}, \mathrm{n}=26$. Different lowercase letters accompanying value bars indicate significant difference by Tukey's multiple comparison test 

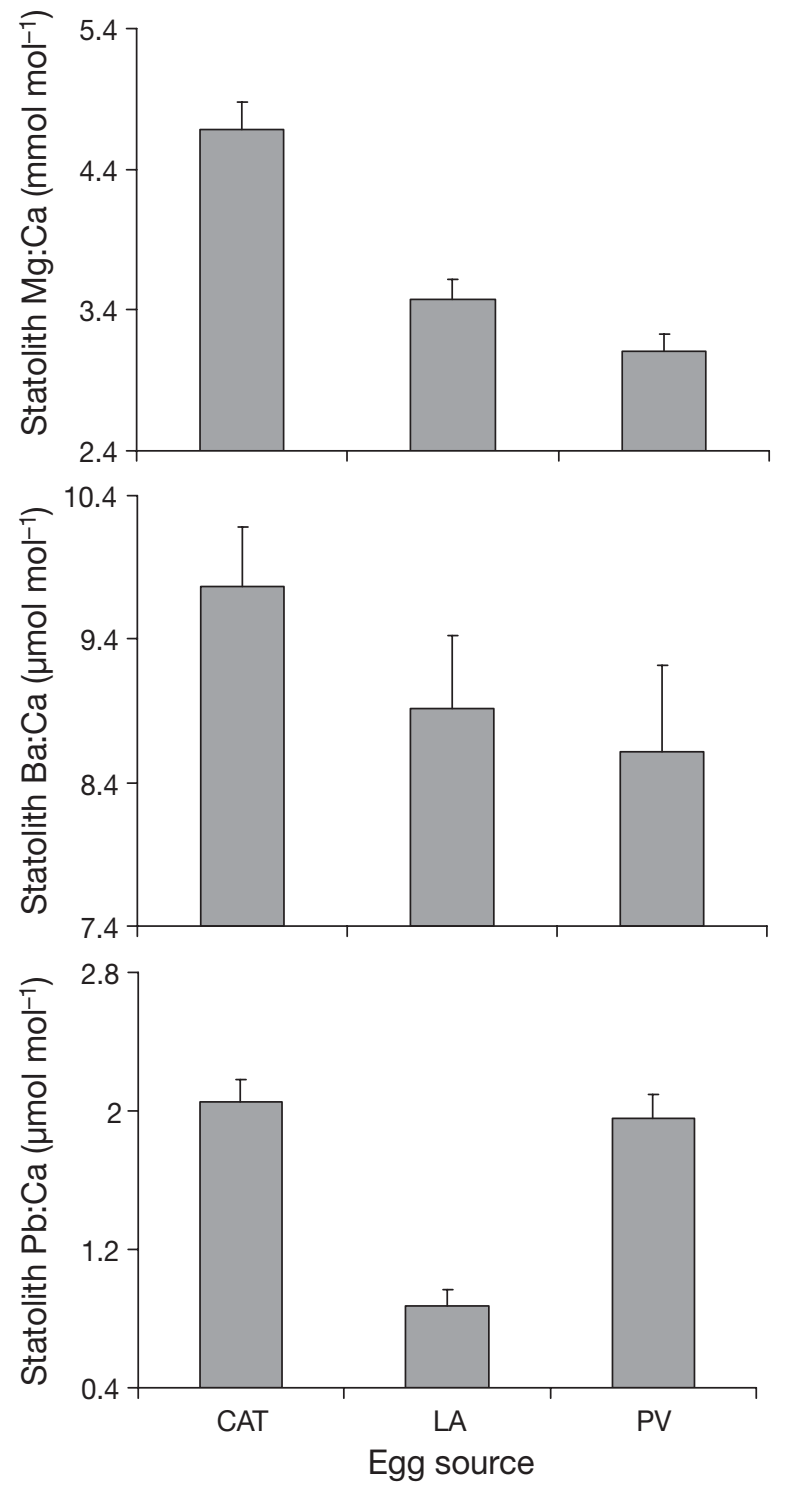

Fig. 3. Kelletia kelletii. Mean (+SE) element-to-calcium ratios in statoliths of laboratory reared larvae plotted against egg source. Means are over all temperature and culture seawater treatments for larvae from each site

Seawater effects. Culture seawater significantly $(p<$ 0.05) affected larval statolith element signatures for $\mathrm{Ba}: \mathrm{Ca}$ and $\mathrm{Pb}: \mathrm{Ca}$, but did not significantly affect elemental signatures for $\mathrm{Mg}: \mathrm{Ca}, \mathrm{Sr}: \mathrm{Ca}, \mathrm{Mn}: \mathrm{Ca}$ or $\mathrm{Zn}: \mathrm{Ca}$ (Table 2). We found significant relationships between element-to-calcium ratios in larval statoliths and element-to-calcium ratios in the culture seawater $\mathrm{Ba}: \mathrm{Ca}$ $\left(F_{2,1161}=8.53, \mathrm{p}=0.007\right)$ and $\mathrm{Pb}: \mathrm{Ca}\left(F_{2,1161}=11.11, \mathrm{p}=\right.$ $0.003)$. Elemental ratios in statoliths averaged over all temperature and egg-source treatments plotted against culture seawater elemental ratios showed positive trends (Fig. 4a,b). Although seawater Mn:Ca was
Table 2. Kelletia kelletii. Nested 3-way ANOVA of statolith elemental ratios from larvae cultured in treatments of 3 factors: $\mathrm{E}=$ egg source, $\mathrm{T}=$ temperature, $\mathrm{W}=$ culture seawater. Nested within each treatment are 10 statoliths ablated per slide, $n=5$ for each treatment. Significant p-values $(<0.05)$ in bold

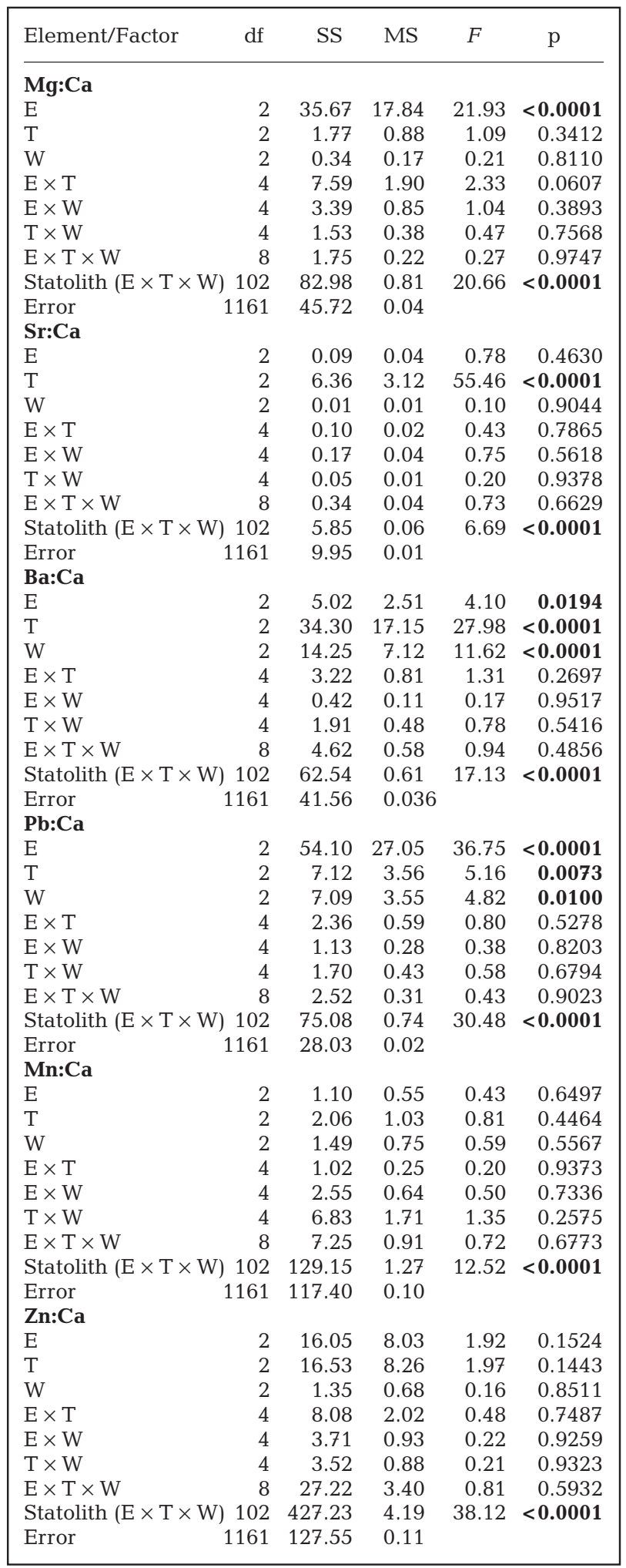


different among sites, statolith Mn:Ca was not, and there is no relationship between statolith and seawater Mn:Ca $\left(F_{2,1161}=0.01, \mathrm{p}=0.914\right.$; Fig. 4c $)$.

Temperature effects. Temperature significantly $(\mathrm{p}<$ 0.05) affected the element-to-calcium ratios in larval statoliths for $\mathrm{Sr}: \mathrm{Ca}, \mathrm{Ba}: \mathrm{Ca}$ and $\mathrm{Pb}: \mathrm{Ca}$, but did not affect statolith elemental ratios of $\mathrm{Mg}: \mathrm{Ca}, \mathrm{Mn}: \mathrm{Ca}$ or
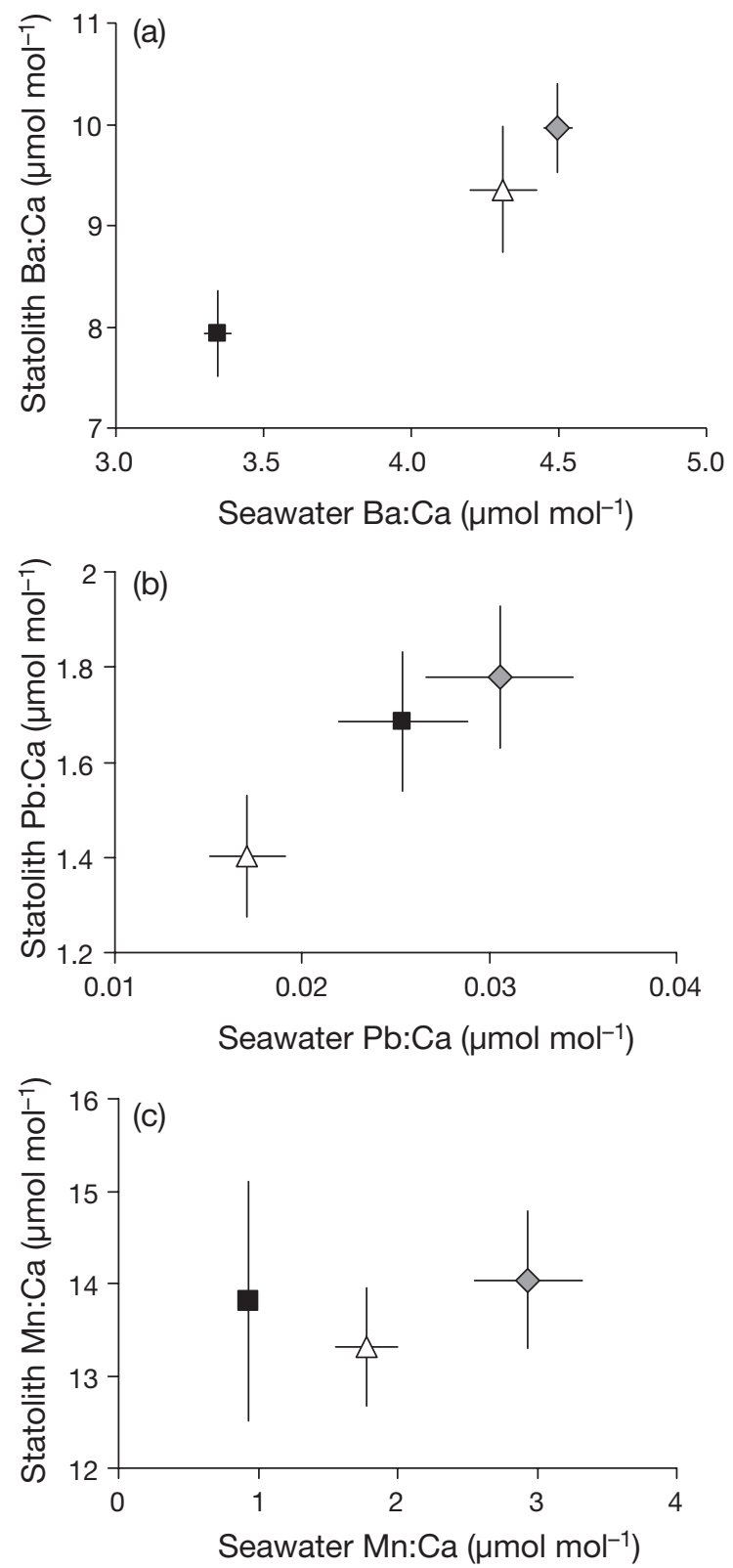

Fig. 4. Kelletia kelletii. Mean $( \pm \mathrm{SE})$ element-to-calcium ratios of larval statoliths plotted against element-to-calcium ratios in culture seawater for (a) Ba:Ca $\left(F_{1,25}=8.53, \mathrm{p}=0.0073\right)$, (b) $\mathrm{Pb}: \mathrm{Ca}\left(F_{1,25}=11.11, \mathrm{p}=0.0027\right)$ and $(\mathrm{c}) \mathrm{Mn}: \mathrm{Ca}\left(F_{1,25}=0.01, \mathrm{p}=\right.$ $0.9139) ; \mathrm{n}=27$. Points are means over all temperature and egg-source treatments for statoliths cultured in water from each site vs. means of culture seawater from each site. Symbols indicate culture seawater source: $\mathbf{\square}=\mathrm{CAT}, \diamond=\mathrm{LA}, \Delta=\mathrm{PV}$
Zn:Ca (Table 2). We found significant relationships for $\mathrm{Sr}$ :Ca $\left(F_{2,1161}=119.34, \mathrm{p}<0.0001\right), \mathrm{Ba}: \mathrm{Ca}\left(F_{2,1161}=\right.$ 27.23, $\mathrm{p}<0.0001)$ and Pb:Ca $\left(F_{2,1161}=4.50, \mathrm{p}=\right.$ 0.044). Element-to-calcium ratios in larval statoliths averaged over all egg-source and seawater treatments plotted against temperature showed strong negative trends (Fig. 5).
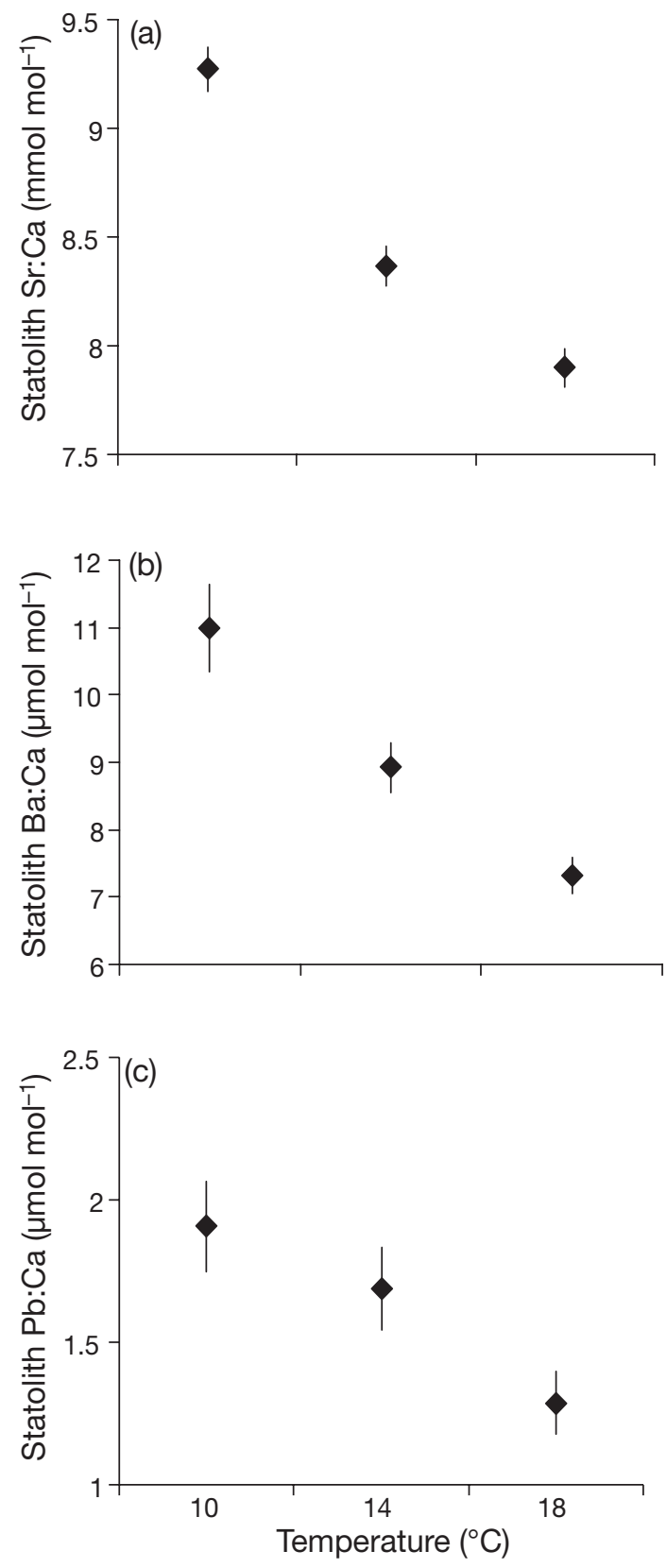

Fig. 5. Kelletia kelletii. Mean $( \pm \mathrm{SE})$ element-to-calcium in larval statoliths plotted against culture temperature for (a) $\mathrm{Sr}$ :Ca $\left(F_{1,25}=119.34, \mathrm{p}<0.0001\right)$, (b) Ba:Ca $\left(F_{1,25}=27.23, \mathrm{p}<0.0001\right)$ and (c) $\mathrm{Pb}: \mathrm{Ca}\left(F_{1,25}=4.50, \mathrm{p}=0.0440\right) ; \mathrm{n}=27$ 


\section{Intracapsular contents}

Analysis of the entire intra-capsular contents of newly laid egg capsules sampled at each site revealed that Sr:Ca $\left(F_{2,27}=10.42, \mathrm{p}=0.0004\right), \mathrm{Ba}: \mathrm{Ca}\left(F_{2,27}=\right.$ 34.02, $\mathrm{p}<0.0001)$, $\mathrm{Pb}: \mathrm{Ca}\left(F_{2,27}=18.97, \mathrm{p}<0.0001\right)$, $\mathrm{Mn}: \mathrm{Ca}\left(F_{2,27}=12.06, \mathrm{p}=0.0002\right)$ and $\mathrm{Zn}: \mathrm{Ca}\left(F_{2,27}=\right.$ 4.30, $\mathrm{p}=0.0238)$ were significantly $(\mathrm{p}<0.05)$ different among sites, while Mg: Ca ( $\mathrm{p}=0.6412)$ was not (Fig. 6). Relationships between element-to-calcium ratios in larval statoliths and elemental ratios in intra-capsular contents were not significant for $\mathrm{Mg}$ : Ca $(\mathrm{p}=0.376)$, $\mathrm{Ba}: \mathrm{Ca}(\mathrm{p}=0.425)$ or $\mathrm{Pb}: \mathrm{Ca}(\mathrm{p}=0.377)$ based on ANOVA (Fig. 7).

\section{Relative importance of factors}

Both $\mathrm{Ba}: \mathrm{Ca}$ and $\mathrm{Pb}: \mathrm{Ca}$ in statoliths were affected by all 3 factors, including egg source, temperature and culture water (Table 3). Within the constraints of the variation measured in this study for each factor, we found that for $\mathrm{Pb}: \mathrm{Ca}$, the most influential factor was egg source (i.e. where the eggs were laid), followed by temperature and culture seawater, although the latter 2 factors may have the same effect sizes (Table 3). In contrast, effect sizes for Ba:Ca show that temperature was the most influential factor, followed by culture seawater and egg source (Table 3 ). The effect size estimates for other elements confirm the significance of factors with an effect. Statolith Mg:Ca was most influenced by egg source and Sr:Ca was most influenced by temperature (Tables $2 \& 3$ ).

\section{DISCUSSION}

\section{Egg-source effects}

This is the first study to show that egg source may be a significant factor that contributes to among-site differences in natal elemental signatures of larval
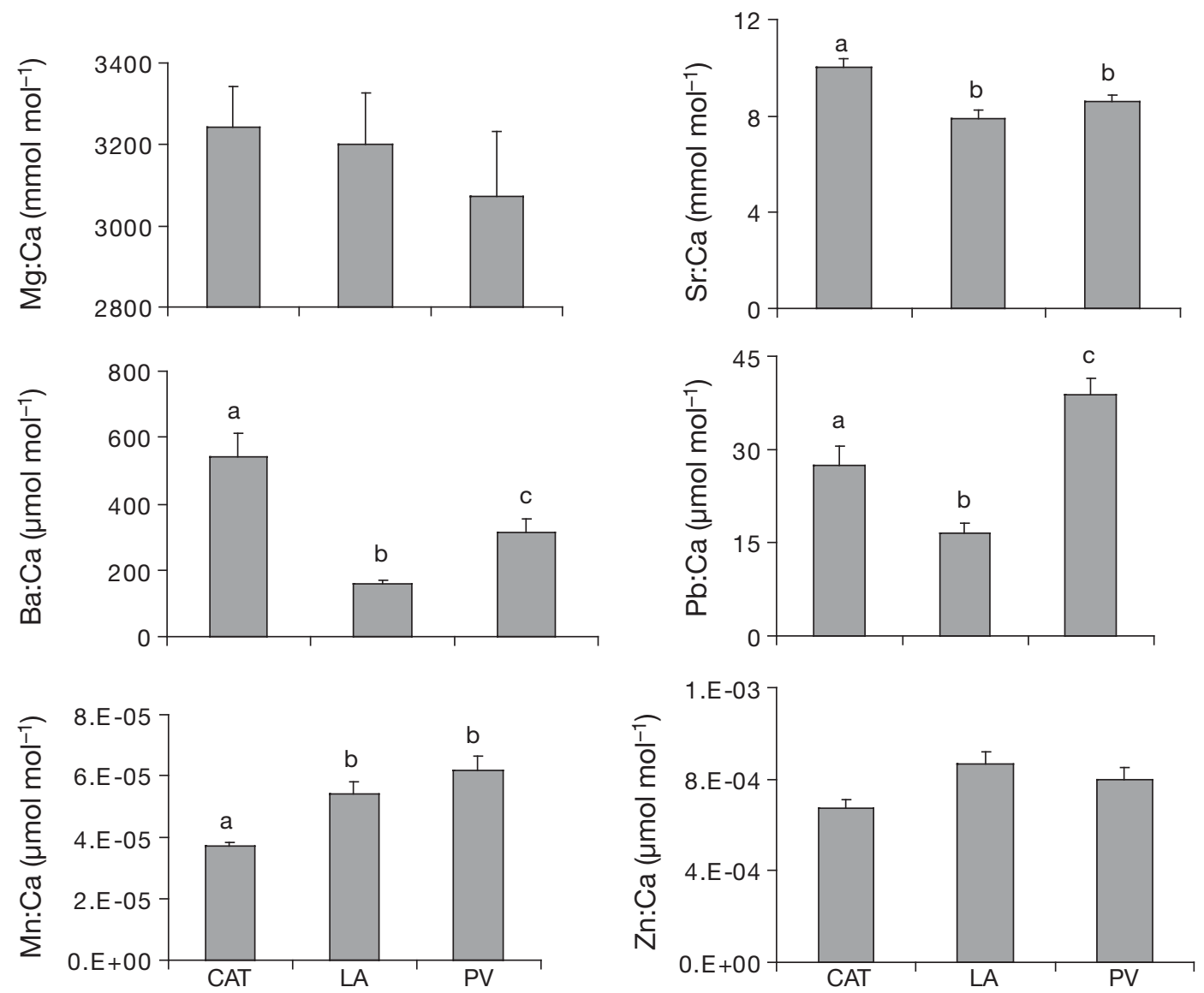

Site

Fig. 6. Mean (+SE) intra-capsular element-to-calcium ratios across site. Different lowercase letters accompanying value bars indicate significant difference by Tukey's multiple comparison procedure 

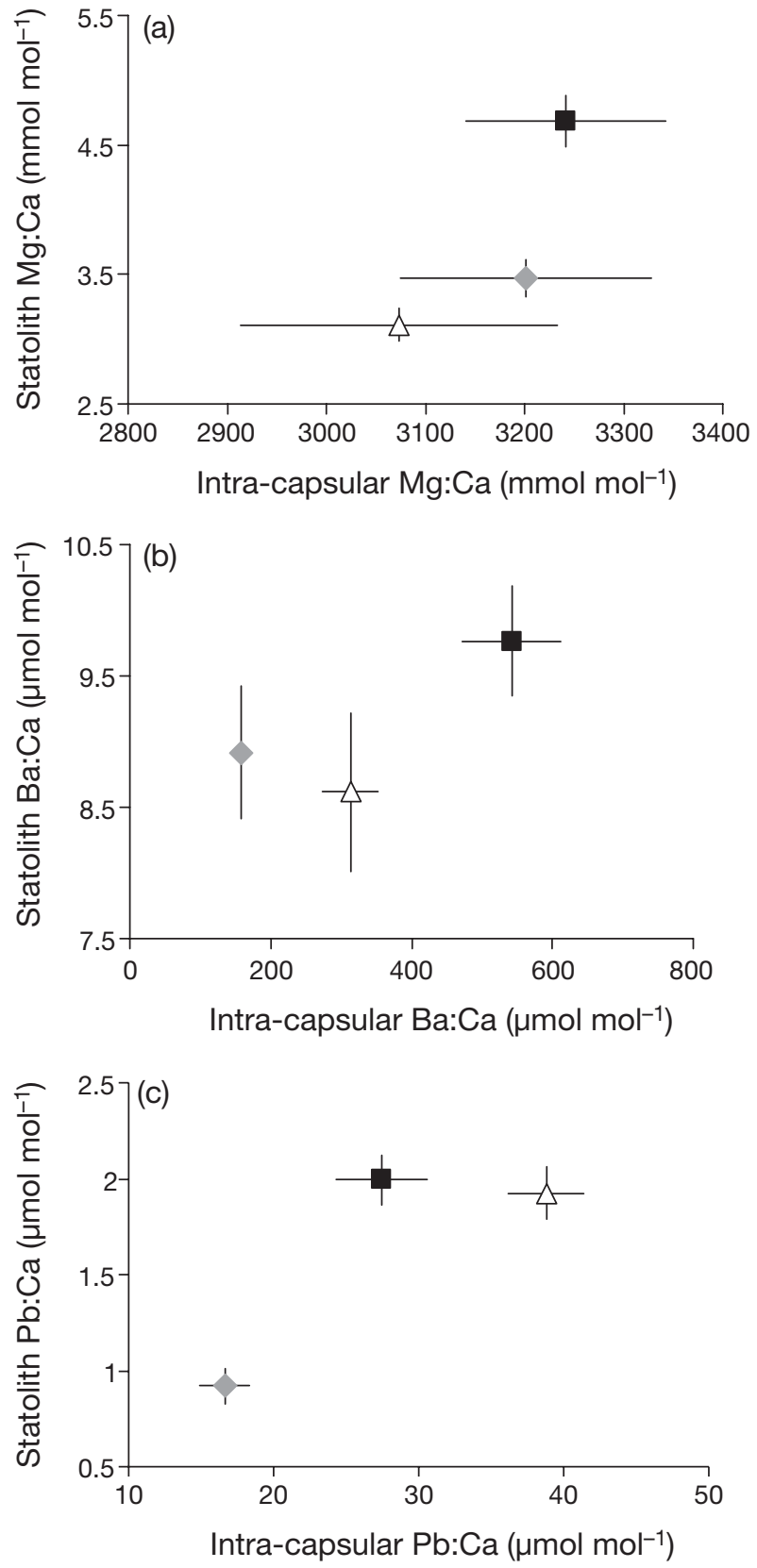

Fig. 7. Kelletia kelletii. Mean $( \pm \mathrm{SE})$ element-to-calcium ratios of larval statoliths plotted against intra-capsular element-tocalcium ratios for (a) $\mathrm{Mg}$ :Ca $\left(F_{1,1}=2.23, \mathrm{p}=0.3757\right)$, (b) Ba:Ca $\left(\mathrm{F}_{1,1}=1.61, \mathrm{p}=0.4246\right)$ and $(\mathrm{c}) \mathrm{Pb}: \mathrm{Ca}\left(F_{1,1}=2.21, \mathrm{p}=0.3773\right)$; $\mathrm{n}=3$. Points are means over all temperature and culture seawater treatments for statoliths from each egg-source treatment vs. means of intra-capsular contents. Symbols indicate egg capsule source: $\mathbf{\square}=\mathrm{CAT}, \nabla=\mathrm{LA}, \Delta=\mathrm{PV}$

statoliths. These egg-source effects must be due to factors unique to an area or population of individuals. For example, prey items consumed by Kelletia kelletii differ among sites (D. C. Zacherl pers. obs.), and element uptake or bioaccumulation in these prey items may dif-
Table 3. Partial $\eta^{2}$ measure of relative importance of main effects on statolith elemental signatures. CI $=95 \%$ confidence intervals calculated using bootstrap procedures, $\mathrm{E}=$ egg source, $\mathrm{T}=$ temperature, $\mathrm{W}=$ culture seawater, ${ }^{*} \mathrm{p}<0.05$

\begin{tabular}{|lccr|}
\hline Element/Factor & Partial $\eta^{2}$ & Lower CI & Upper CI \\
\hline Mg:Ca & & & \\
E & $31.80^{*}$ & 21.00 & 45.70 \\
W & 0.26 & 0.05 & 7.06 \\
T & 1.40 & 0.0004 & 3.43 \\
Sr:Ca & & & \\
E & 1.57 & 0.19 & 12.12 \\
W & 0.16 & 0.04 & 7.22 \\
T & $52.10^{*}$ & 38.70 & 69.73 \\
Ba:Ca & & & \\
E & $6.91^{*}$ & 2.10 & 21.50 \\
W & $17.35^{*}$ & 8.38 & 33.40 \\
T & $33.80^{*}$ & 26.40 & 49.50 \\
Pb:Ca & & & \\
E & $41.50^{*}$ & 28.40 & 57.80 \\
W & $8.40^{*}$ & 2.33 & 20.63 \\
T & $8.72^{*}$ & 2.21 & 21.70 \\
Mn:Ca & & & \\
E & 0.90 & 0.10 & 8.82 \\
W & 0.71 & 0.08 & 9.38 \\
T & 1.77 & 0.003 & 7.58 \\
Zn:Ca & & & \\
E & 4.04 & 0.30 & 17.68 \\
W & 0.32 & 0.07 & 6.72 \\
T & 3.97 & 0.002 & 8.62 \\
\hline
\end{tabular}

fer depending on the prey species (e.g. Deheyn \& Latz 2006). In addition, the bioavailability of elements to the mother from ambient seawater may vary among sites (e.g. Geffen et al. 2003) due to variation in the input (e.g. runoff, atmospheric deposition) and removal of elements in seawater (e.g. sorption onto substrate and suspended particles). Therefore, the maternal contribution of elements to the yolk and egg cells may be influenced by elements in the diet or water.

Compelling evidence exists to suggest that elements deposited in yolk can be incorporated into fish otoliths. Volk et al. (2000) crossed captive salmonid fishes reared in freshwater to wild anadromous salmonids and reared the progeny in a common environment. They found that the progeny's otolith $\mathrm{Sr}: \mathrm{Ca}$ signature reflected the origin of the female; otoliths of larvae from freshwater females had very low levels of $\mathrm{Sr}: \mathrm{Ca}$ compared with otoliths of larvae from seawater females. Volk et al. (2000) were also able to clearly distinguish between the progeny of salmon in a channel where freshwater captive adults spawned with wild anadromous adults, demonstrating that the maternal origins of salmon can be distinguished based on Sr:Ca otolith signatures. Perhaps most convincingly, Thorrold et al. (2006) demonstrated trans-generational transfer of ${ }^{137} \mathrm{Ba}$ by injecting the isotope into the abdominal cavity of gravid female 
Amphiprion melanopus (benthic-spawning coral reef fish) and Centropristis striata (planktonic-spawning temperate reef fish) using a range of dosages (0.45 to $23 \mu \mathrm{g} \mathrm{g}^{-1}$ ). Eggs of both species were reared to settlement in a controlled environment before otolith extraction. Analysis of embryonic otoliths revealed that larvae of both species had incorporated maternal ${ }^{137} \mathrm{Ba}$. Transects across the otolith showed ${ }^{137} \mathrm{Ba}$ only in the embryonic core, which corresponded to the period of yolk absorption; thus, ${ }^{137} \mathrm{Ba}$ was presumably transferred via the yolk to the embryonic otoliths. Importantly, despite the fact that planktonic-spawned eggs have relatively less yolk than benthic-spawned eggs, ${ }^{137}$ Ba was easily detected in embryonic otoliths of planktonic-spawned larvae.

Our results show clear egg-source effects in that $\mathrm{Mg}: \mathrm{Ca}$ and $\mathrm{Ba}: \mathrm{Ca}$ were higher in statoliths from CAT and $\mathrm{Pb}: \mathrm{Ca}$ was lowest in statoliths from LA, regardless of the origin of the culture seawater or the temperature treatment (Fig. 3). We found no clear relationships between intra-capsular and statolith chemistry for Mg:Ca, Ba:Ca and Pb:Ca (Fig. 7); the lack of statistical significance was perhaps due to lack of statistical power from the small sample sizes used $(n=3)$. While the egg-source effect might have been partly influenced by incorporation of elements from yolk into larval statoliths (Fig. 7), some other factor obscured the relationships or the egg-source effect was due to some other aspect specific to each site. Clearly, the mechanism driving the egg-source effect warrants further investigation.

Results for $\mathrm{Pb}: \mathrm{Ca}$ in samples from LA were particularly interesting. Statoliths from LA had the lowest values of $\mathrm{Pb}: \mathrm{Ca}$ (Fig. 3) regardless which treatment the larvae had been cultured in, and the intra-capsular contents (Fig. 6) from LA had the lowest values of $\mathrm{Pb}: \mathrm{Ca}$. However, $\mathrm{Pb}: \mathrm{Ca}$ was highest in the culture seawater from LA (Fig. 2). We speculate that perhaps a detoxification mechanism could be contributing to the low $\mathrm{Pb}$ baseline in adult and/or larval Kelletia kelletii from Los Angeles Harbor. Adaptation to heavy metals in populations of a variety of aquatic taxa (including bivalves and gastropods) exposed to polluted environments has been documented (see review by Klerks \& Weis 1987). Detoxification methods known to occur in some gastropods include metal-binding proteins (e.g. Han et al. 2003) and sequestration in metal-containing granules within digestive gland cells (e.g. Mason \& Nott 1981). While the populations at our study sites may be too close in proximity to produce local adaptation, perhaps phenotypic plasticity can occur within embayments such as Los Angeles Harbor. Studies examining whether $K$. kelletii exhibits any methods of heavy metal detoxification would improve our understanding of these results.
Natural element tagging has been of limited utility for larvae of broadcast spawners (but see Becker et al. 2007), because the larvae develop their calcified structures after release into the plankton and researchers have previously assumed that variation in statolith/ otolith chemistry is primarily due to environmental conditions (Ruttenberg et al. 2005, Chittaro et al. 2006). Consequently, the assumption has been that larvae of planktonic spawners form calcified structures whose elemental signatures reflect environmental conditions encountered in the plankton rather than signatures representative of their natal site. However, this first empirical demonstration that egg source affects elemental signatures of larval calcified structures implies that it may even be possible to track larvae of planktonic spawners if they incorporate elements reflective of their egg source during yolk consumption. The findings that the egg-source effect on statolith $\mathrm{Pb}$ :Ca overwhelmed the effects due to the environment (Fig. 3) and that egg source was statistically the most significant factor influencing $\mathrm{Pb}$ uptake into statoliths (Table 3) provide provocative evidence that larvae of planktonic spawners might be 'tagged' by their natal site despite never spending any time there.

\section{Culture seawater effects}

We found significant positive relationships between culture seawater and statolith chemistry for Ba:Ca and $\mathrm{Pb}: \mathrm{Ca}$ (Fig. 4), confirming past work that showed Ba:Ca (e.g. Zacherl et al. 2003) and Pb:Ca (Geffen et al. 1998, Milton \& Chenery 2001) increase in calcified structures with increasing seawater concentration. These results contrast those found by Warner et al. (2005), who found no relationship between ambient levels of these elements and the trace element composition of natal otoliths of fish. This contrast might be due to differences in physiology between the species studied. A brief comparison of uptake of $\mathrm{Mg}: \mathrm{Ca}, \mathrm{Sr}: \mathrm{Ca}$ and $\mathrm{Ba}: \mathrm{Ca}$ in coral skeletons, bivalve shells, squid statoliths and fish otoliths showed that discrimination of elements tended to be least for the simplest animals, with more discrimination occurring in more complex animals (Campana 1999). Another explanation is that Warner et al. (2005) conducted a field study, which was subject to environmental variation with multiple factors probably affecting otolith chemistry, whereas we conducted a controlled laboratory study and were able to isolate seawater effects. Finally, the relationship we found between statolith and seawater chemistry may be an artifact of using a single sample of water from each site for the cultures, while Warner et al. (2005) used the average of several seawater samples taken at each site over time to correlate to otolith chemistry. 
Warner et al. (2005) attempted to link seawater and a resin-based element accumulator as proxies for otolith elemental signatures in an open-coast fish. However, they found only Mn concentrations to be similar between otolith chemistry and the 2 physical proxies, with qualitative regional patterns being similar over 2 yr. Multiple field studies have found Mn in calcified structures useful for discriminating among individuals from different sites (e.g. DiBacco \& Levin 2000, Geffen et al. 2003), and correlative studies on coral aragonite have found that $\mathrm{Mn}$ :Ca ratios are inversely related to upwelling intensity (e.g. Delaney et al. 1993). However, no laboratory studies have conclusively demonstrated relationships between $\mathrm{Mn}$ in calcified structures and $\mathrm{Mn}$ in seawater. We found that while $\mathrm{Mn}: \mathrm{Ca}$ was significantly different in the culture seawater among 3 sites, no significant difference in statolith Mn:Ca signatures existed among the sites (Table 2), and no significant relationship existed between statolith and seawater Mn:Ca (Fig. 4c).

In fact, it has proven difficult to experimentally pinpoint the factors responsible for Mn signatures in calcified structures. Bath Martin \& Thorrold (2005) found no effect of temperature or salinity on $\mathrm{Mn}$ :Ca ratios in otoliths. The authors detected changes in Mn:Ca over time in the culture seawater, which they attributed to bacterial oxidation of Mn that may have been responsible for part of the variation in otolith $\mathrm{Mn}: \mathrm{Ca}$. Two other studies also did not find an effect of temperature and/or salinity (Elsdon \& Gillanders 2002) or seawater (Elsdon \& Gillanders 2003) on Mn:Ca ratios in fish otoliths. Our results are similar to the results in those studies. As with Bath Martin \& Thorrold (2005), Mn:Ca in our culture seawater samples was significantly different among experiment days, with Mn:Ca decreasing over time. Microbial oxidation rapidly oxidizes dissolved Mn in marine systems (e.g. Rosson \& Nealson 1982), and we observed some bacterial growth in the culture flasks despite regular $50 \%$ water changes. As in Bath Martin \& Thorrold (2005), bacterial oxidation may have occurred during our experiment causing dissolved Mn to decrease over time, meaning our results concerning Mn must be interpreted with caution.

The crystal structure of calcium carbonate affects incorporation of elements in bivalve shells (Onuma et al. 1979). The most common forms of biogenic carbonates are orthorhombic aragonite and rhombohedral calcite (White et al. 1977). Elements with an ionic radius smaller than $\mathrm{Ca}^{2+}$, including $\mathrm{Mn}^{2+}$ and $\mathrm{Zn}^{2+}$, are more likely to fit within a calcite lattice, while elements with an ionic radius greater than $\mathrm{Ca}^{2+}$ are more likely to substitute for $\mathrm{Ca}^{2+}$ in an aragonite lattice (Speer 1983). Brophy et al. (2004) reasoned that the enrichment of $\mathrm{Mn}$ in the otolith core could be a result of the otolith being composed of calcite in the core and then shifting to aragonite outside the core. Although the crystal structure of Kelletia kelletii statoliths has not been determined, relative concentrations of $\mathrm{Mg}^{2+}, \mathrm{Sr}^{2+}$, $\mathrm{Ba}^{2+}$ and $\mathrm{Pb}^{2+}$ suggest that aragonite formation would be favored over calcite (Carlström 1963). Statoliths composed mostly of aragonite would be less likely to incorporate $\mathrm{Mn}$, and this may at least partly explain why statolith Mn:Ca did not differ among sites even though seawater Mn:Ca did.

\section{Temperature effects}

We found strong, significant, inverse relationships between temperature and statolith $\mathrm{Sr}: \mathrm{Ca}, \mathrm{Ba}: \mathrm{Ca}$ and $\mathrm{Pb}: \mathrm{Ca}$ (Fig. 5). Our results support past research that shows $\mathrm{Sr}: \mathrm{Ca}$ and $\mathrm{Ba}: \mathrm{Ca}$ vary inversely with temperature in gastropod statoliths (Zacherl et al. 2003). In addition, to our knowledge, we have provided the first empirical demonstration of a negative relationship between statolith $\mathrm{Pb}: \mathrm{Ca}$ and temperature. Since $\mathrm{Pb}^{2+}$ and $\mathrm{Sr}^{2+}$ have similar ionic radii, $\mathrm{Pb}^{2+}$ might behave similarly to $\mathrm{Sr}^{2+}$ during incorporation in $\mathrm{CaCO}_{3}$. Our results are consistent with circumstantial evidence showing that average core $\mathrm{Pb}:{ }^{43} \mathrm{Ca}$ signatures in European hake Merluccius merluccius otoliths were 1 order of magnitude higher at sites in the northeast Atlantic Ocean with a mean annual temperature of $8.9^{\circ} \mathrm{C}$ than in otoliths of fish from the western Mediterranean Sea with a mean annual temperature of $13.7^{\circ} \mathrm{C}$ (MoralesNin et al. 2005). More studies are needed to understand the relationship between temperature and $\mathrm{Pb}: \mathrm{Ca}$ in calcified structures.

\section{Relative importance of factors}

Only one other study has attempted to estimate the relative effects of factors on elemental uptake in calcified structures. Elsdon \& Gillanders (2004) attempted to determine the relative effects of temperature, salinity, ambient $\mathrm{Sr}$ and $\mathrm{Ba}$ concentration and the interactions among these factors on otoliths of juvenile black bream. They used a backwards step-wise regression, which allowed the elimination of salinity from the model because it did not significantly affect otolith elemental signatures. Their analysis demonstrated that of the 3 factors, temperature and ambient elemental concentration influence otolith chemistry, but did not provide an estimate of the magnitude of effect of each factor.

Effect-size analyses are used infrequently in ecological literature, yet such analyses can be useful for estimating statistical fit in complicated factorial studies (Graham 2001). Here we must point out 2 caveats 
regarding the use of effect-size estimates. First, the effect-size measure $\eta^{2}$ tends to overestimate effect sizes, thus comparing effect sizes across elements must be done with caution. Second, effect-size estimates are of limited utility in studies that do not explore the full range of variation in the factors tested. To see if the effect-size estimates were true for this study we calculated a second measure of effect size for the main effects as follows:

\section{Large Mean - Small Mean $\sqrt{\mathrm{MS}_{\mathrm{error}}}$}

Where Large Mean is the largest mean in a group (i.e. egg source, culture seawater or temperature) and Small Mean is the smallest mean in the same group. In fact both measures of effect size were exactly correlated and yielded the same ranking of importance; consequently we only report $\eta^{2}$ because it is the most appropriate for estimating the relative importance of each factor. The field temperature results show that we successfully bracketed the range of temperatures experienced by Kelletia kelletii at the collection sites (Table 1), and in fact we bracketed the full range of temperatures experienced by $K$. kelletii throughout its range. However, we only collected one sample of seawater at each site and probably did not bracket the full range of variation in seawater elemental concentrations across $K$. kelletii's range. We have only begun to discover egg-source effects and we certainly do not know the full extent of variation produced by these effects, although the fact that egg source was the most important factor affecting $\mathrm{Pb}$ signatures in this study (Table 3) indicates that it can potentially be powerful.

Within the constraints of the variation measured in this study for each factor we found that for $\mathrm{Pb}$ :Ca the most influential factor was egg source, while effects sizes for $\mathrm{Ba}: \mathrm{Ca}$ showed that temperature was the most influential factor. While these effect-size estimates are only applicable to the variation measured in the parameters of this particular study, the results show that elements responded differently to the same factors. Consequently it seems that predicting elemental signatures will require an understanding of what elements are bio-available, what factors in the area can affect each element and how those elements are influenced by each factor, all at an appropriate scale.

\section{CONCLUSION}

We demonstrated that egg source affects statolith elemental signatures in Kelletia kelletii larvae, that elements may be influenced by a number of factors, as was the case for $\mathrm{Ba}$ and $\mathrm{Pb}$ (Table 2), and that the most influential factor on the statolith signature of one element may not be the most influential factor for another element (Table 3). Our results also support past research showing that $\mathrm{Ba}: \mathrm{Ca}$ and $\mathrm{Pb}: \mathrm{Ca}$ tend to increase in $K$. kelletii larval statoliths with increasing concentration in seawater (Fig. 4a,b), and that Sr:Ca and $\mathrm{Ba}: \mathrm{Ca}$ in $K$. kelletii larval statoliths tend to decrease with increasing temperature (Fig. 5a,b). Finally, we provided the first evidence that $\mathrm{Pb}$ may also decrease with increasing temperature (Fig. 5c).

The use of seawater samples as a proxy for elemental signatures in calcified structures seems less promising given the number of factors and their possible interactions that can influence element uptake. This (Table 3) and past studies (Bath et al. 2000, Elsdon \& Gillanders 2002, 2003) have clearly demonstrated that elements in calcified structures respond differently to various factors. We now know that not only environmental variables affect element signatures, but egg source can too. In addition, endogenous factors such as ontogenic effects (e.g. De Pontual et al. 2003, Chittaro et al. 2006), growth rate (Bath Martin \& Thorrold 2005) and the type of $\mathrm{CaCO}_{3}$ crystal present in various regions of the otolith (Brophy et al. 2004, Ruttenberg et al. 2005) can affect elemental signatures and further complicate the use of seawater samples as a proxy for elemental signatures in calcified structures. Finally, because so many factors can influence the chemistry of calcified structures, it may not be appropriate to use statoliths or otoliths to reconstruct environmental histories in the field unless the influential factors have been validated.

Use of statoliths for larval tracking remains a promising prospect, however, because site-specific natal signatures can be used as long as they are spatially distinct and temporally stable over the time period of interest. Given that egg-source effects exist, this tool might someday be applied to larval tracking studies using larval statoliths or shells of planktonic spawners among whose representatives are some that support the most commercially important invertebrate fisheries (e.g. abalone, mussels, oysters).

Acknowledgements. We thank S. Koch, M. Navarro, J. Kurts, A. Willingham, D. Smith, G. Smith and T. Oudin for helping with field work, M. Romero and D. B. Lloyd for help with the laboratory work, S. Murray for his valuable comments and Wildlife Supply Co. for their complementary repair of our Van Dorn sampler. The following provided funding: Minority Science Development-National Institute of Health Research Grant, California State University Fullerton Associated Students Incorporated, Biology Department Research Grants, Women's Environmental Council, National Science Foundation OCE 0351860, and the Partnership for the Interdisciplinary Study of Coastal Oceans (funded by the Packard Foundation and the Moore Foundation). 


\section{LITERATURE CITED}

Bath G, Thorrold SR, Jones CM, Campana SE, McLaren JW, Lam JWH (2000) Strontium and barium uptake in aragonitic otoliths of marine fish. Geochim Cosmochim Acta 64: 1705-1714

Bath Martin G, Thorrold SR (2005) Temperature and salinity effects on magnesium, manganese, and barium incorporation in otoliths of larval and early juvenile spot Leiostomus xanthurus. Mar Ecol Prog Ser 293:223-232

Becker BJ, Levin LA, Fodrie FJ, McMillan PA (2007) Complex larval connectivity patterns among marine invertebrate populations. Proc Natl Acad Sci USA 104:3267-3272

Brophy D, Jeffries TE, Danilowicz BS (2004) Elevated manganese concentrations at the cores of clupeid otoliths: possible environmental, physiological, or structural origins. Mar Biol 144:779-786

Campana SE (1999) Chemistry and composition of fish otoliths: pathways, mechanisms and applications. Mar Ecol Prog Ser 188:263-297

Campana SE, Chouinard GA, Hanson JM, Frechet A, Brattey $\mathrm{J}$ (2000) Otolith elemental fingerprints as biological tracers of fish stocks. Fish Res 46:343-357

Carlström D (1963) A crystallographic study of vertebrate otoliths. Biol Bull (Woods Hole) 124:441-463

Chang CW, Lin SH, Iizuka Y, Tzeng WN (2004) Relationship between Sr:Ca ratios in otoliths of grey mullet Mugil cephalus and ambient salinity: validation mechanisms and applications. Zool Stud 43:74-85

Chittaro PM, Hogan JD, Gagnon J, Fryer BJ, Sale PF (2006) In situ experiment of ontogenetic variability in the otolith chemistry of Stegastes partitus. Mar Biol 149:1227-1235

Deheyn DD, Latz MI (2006) Bioavailability of metals along a contamination gradient in San Diego Bay (California, USA). Chemosphere 63:818-834

Delaney ML, Linn LJ, Druffel ERM (1993) Seasonal cycles of manganese and cadmium in coral from the Galápagos Islands. Geochim Cosmochim Acta 57:347-354

De Pontual H, Lagardere F, Amara R, Bohn M, Ogor A (2003) Influence of ontogenetic and environmental changes in the otolith microchemistry of juvenile sole (Solea solea). J Sea Res 50:199-210

DiBacco C, Levin LA (2000) Development and application of elemental fingerprinting to track the dispersal of marine invertebrate larvae. Limnol Oceanogr 45:871-880

Elsdon TS, Gillanders BM (2002) Interactive effects of temperature and salinity on otolith chemistry: challenges for determining environmental histories of fish. Can J Fish Aquat Sci 59:1796-1808

Elsdon TS, Gillanders BM (2003) Relationship between water and otolith elemental concentrations in juvenile black bream Acanthopagrus butcheri. Mar Ecol Prog Ser 260: 263-272

Elsdon TS, Gillanders BM (2004) Fish otolith chemistry influenced by exposure to multiple environmental variables. J Exp Mar Biol Ecol 313:269-284

Farrell J, Campana SE (1996) Regulation of calcium and strontium deposition on the otoliths of juvenile tilapia, Oreochromis niloticus. Comp Biochem Physiol 115A: 103-109

Fidler F, Thompson B (2001) Computing correct confidence intervals for ANOVA fixed- and random-effects effect sizes. Educ Psychol Meas 61:575-604

Geffen AJ, Pearce NJG, Perkins WT (1998) Metal concentrations in fish otoliths in relation to body composition after laboratory exposure to mercury and lead. Mar Ecol Prog Ser 165:235-245
Geffen AJ, Jarvis K, Thorpe JP, Leah RT, Nash RDM (2003) Spatial differences in the trace element concentrations of Irish Sea plaice Pleuronectes platessa and whiting Merlangius merlangus otoliths. J Sea Res 50:245-254

Gillanders BM (2002) Temporal and spatial variability in elemental composition of otoliths: implications for determining stock identity and connectivity of populations. Can J Fish Aquat Sci 59:669-679

Gillanders BM, Kingsford MJ (2003) Spatial variation in elemental composition of otoliths of three species of fish (family Sparidae). Estuar Coast Shelf Sci 57:1049-1064

Graham MH (2001) Statistical significance versus fit: estimating the importance of individual factors in ecological analysis of variance. Oikos (Forum) 93:3

Grissom RJ, Kim JJ (2005) Effect sizes for research: a broad practical approach. Lawrence Erlbaum Associates, Mahwah, NJ

Han SJ, Park JS, Lee IS (2003) Accumulation and elimination of cadmium and zinc in the Asian periwinkle Littorina brevicula. J Environ Sci Health Part A Toxic-Hazard Subst Environ Eng 38:965-974

Herrlinger TJ (1981) Range extension of Kelletia kelletii. Veliger 24:78

Ikeda Y, Arai N, Sakamoto W, Mitsuhashi M, Yoshida K (1999) Preliminary report on PIXE analysis for trace elements of Octopus dofleini statoliths. Fish Sci 65:161-162

Ikeda Y, Arai N, Kidokoro H, Sakamoto W (2003) Strontium:calcium ratios in statoliths of Japanese common squid Todarodes pacificus (Cephalopoda: Ommastrephidae) as indicators of migratory behavior. Mar Ecol Prog Ser 251:169-179

Klerks PL, Weis JS (1987) Genetic adaptation to heavy metals in aquatic organisms: a review. Environ Pollut 45:173-205

Lea DW, Shen GT, Boyle EA (1989) Coralline barium records temporal variability in equatorial Pacific upwelling. Nature 340:373-376

Lea DW, Pak DK, Spero HJ (2000) Climate impact of late quaternary equatorial Pacific sea surface temperature variations. Science 289:1719-1724

Limburg KE, Landergren P, Westin L, Elfman M, Kristiansson P (2001) Flexible modes of anadromy in Baltic sea-trout (Salmo trutta): making the most of marginal spawning streams. J Fish Biol 59:682-695

Mason AZ, Nott JA (1981) The role of intracellular biomineralized granules in regulation and detoxification of metals in gastropods with special reference to the marine prosobranch Littorina littorea. Aquat Toxicol 1:239-256

Milton DA, Chenery SR (2001) Sources and uptake of trace metals in otoliths of juvenile barramundi Lates calcarifer. J Exp Mar Biol Ecol 264:47-65

Morales-Nin B, Swan SC, Gordon JDM, Palmer M, Geffen AJ, Shimmield T, Sawyer T (2005) Age-related trends in otolith chemistry of Merluccius merluccius from the northeastern Atlantic Ocean and the western Mediterranean Sea. Mar Freshw Res 56:599-607

Oakden JM, Oliver JS, Flegal AR (1984) Behavioral responses of a phoxocephalid amphipod to organic enrichment and trace metals in sediment. Mar Ecol Prog Ser 14:253-257

Onuma N, Masuda F, Hirano M, Wada K (1979) Crystal structure control on trace element partition in molluscan shell formation. Geochem J 13:187-189

Rieman BE, Myers DL, Nielsen RL (1994) Use of otolith microchemistry to discriminate Oncorhynchus nerka of resident and anadromous origins. Can J Fish Aquat Sci 51:68-77

Roff DA (2006) Introduction to computer-intensive methods of data analysis in biology. Cambridge University Press, Cambridge 
Rosenthal RJ (1970) Observations on the reproductive biology of the Kellet's whelk, Kelletia kelletii. Veliger 12: 319-324

Rosenthal Y, Field MP, Sherrell RM (1999) Precise determination of element/calcium ratios in calcareous samples using sector field inductively coupled plasma mass spectrometry. Anal Chem 71:3248-3253

Rosson AR, Nealson KH (1982) Manganese binding and oxidation by spores of a marine bacillus. J Bacteriol 151: 1027-1034

Ruttenberg BI, Hamilton SL, Hickford MJH, Paradis GL and others (2005) Elevated levels of trace elements in cores of otoliths and their potential for use as natural tags. Mar Ecol Prog Ser 297:273-281

Shen GT, Sanford CL (1990) Trace element indicators of climate variability in reef-building corals. In: Glynn PW (ed) Global ecological consequences of the 1982-83 El Niño-Southern Oscillation. Elsevier, Amsterdam, p 255-283

Speer JA (1983) Crystal chemistry and phase relations of the orthorhombic carbonates. Rev Mineral Geochem 11: $145-190$

Stull JK (1995) Two decades of marine biological monitoring, Palos Verdes, California, 1972 to 1992. Bull South Calif Acad Sci 94:21-45

Swearer SE, Caselle JE, Lea DW, Warner RR (1999) Larval retention and recruitment in an island population of a coral reef fish. Nature 402:799-802

Swearer SE, Forrester GE, Steele MA, Brooks AJ, Lea DW (2003) Spatio-temporal and interspecific variation in otolith trace-elemental fingerprints in a temperate estuarine fish assemblage. Estuar Coast Shelf Sci 56:1111-1123

Editorial responsibility: Lisa Levin (Contributing Editor), La Jolla, California, USA
Thorrold SR, Jones CM, Campana SE (1997) Response of otolith microchemistry to environmental variations experienced by larval and juvenile Atlantic croaker (Micropogonias undulatus). Limnol Oceanogr 42:102-111

Thorrold SR, Jones JP, Planes S, Hare JA (2006) Transgenerational marking of embryonic otoliths in marine fishes using barium isotopes. Can J Fish Aquat Sci 63: 1193-1197

Volk EC, Blakley A, Schroder SL, Kuehner SM (2000) Otolith chemistry reflects migratory characteristics of Pacific salmonids: using otolith core chemistry to distinguish maternal associations with sea and freshwaters. Fish Res 46:251-266

Warner RR, Swearer SE, Caselle JE, Sheehy M, Paradis G (2005) Natal trace-elemental signatures in the otoliths of an open-coast fish. Limnol Oceanogr 50:1529-1542

White LK, Szabo P, Carkner P, Chasteen NDJ (1977) An electron paramagnetic resonance study of manganese (II) in the aragonite lattice of a clam shell, Mya arenaria. Phys Chem 81:1420-1424

Zacherl DC (2005) Spatial and temporal variation in statolith and protoconch trace elements as natural tags to track larval dispersal. Mar Ecol Prog Ser 290:145-163

Zacherl DC, Paradis G, Lea D (2003) Ba and Sr uptake into larval protoconchs and statoliths of the marine neogastropod Kelletia kelletii. Geochim Cosmochim Acta 67: 4091-4099

Zhang H, Davison W (1995) Performance characteristics of the technique of diffusive gradients in thin-films (DGT) for the measurement of trace metals in aqueous solutions. Anal Chem 67:3391-3400

Submitted: January 22, 2007; Accepted: July 22, 2007

Proofs received from author(s): December 13, 2007 